\title{
Modernising medical careers
}

\author{
Ed Neville
}

\begin{abstract}
Modernising medical careers proposes the introduction of Basic Medical Training (BMT) programmes to replace senior house officer (SHO) rotations. The current pre-registration house officer year and a broad-based first SHO year will become Foundation Years 1 and 2. This will be followed by a programme with eight options. To become a physician would entail doing the Medical Programme (as distinct from surgical, general practice, etc), and at the end of this a Certificate of Completion of Training in general internal medicine could be awarded. Specialty training will follow sequentially. Advantages, disadvantages and uncertainties of this proposal are discussed.
\end{abstract}

\section{KEY WORDS: Basic Medical Training, Certificate of Completion of Training, foundation years, medical careers, specialty training}

Since the Calman reforms of the registrar grade to amalgamate registrars and senior registrars into specialist registrars it has always been an anomaly that the senior house officer ( $\mathrm{SHO}$ ) training has remained unchanged. It was entirely appropriate, therefore, for this to be addressed by the Chief Medical Officer in Unfinished business which was sent out for consultation with the medical profession in August 2002. ${ }^{1}$ It became obvious from the proposals contained in this document that if SHO training were changed from a mixture of rotations and stand-alone posts to an educational programme there would be knock-on effects on the registrar training grade and on the early part of the consultant career. The subsequent document was released in February 2003 and entitled Modernising medical careers in order to recognise this much wider impact. $^{2}$

\section{Foundation years}

The proposal is that the pre-registration house officer (PRHO) year and the first year as an SHO will be known as Foundation Years 1 and 2 (F1 and F2). Foundation Year 1 is likely to be slightly different from the current PRHO year and may change to three- or four-month modules from the traditional six months of medicine and six months of surgery. Experiments to introduce attachments in primary care at this stage have not been successful but it is likely that there will be space for periods of time in disciplines other than general medicine and surgery. Nevertheless, General Medical Council (GMC) requirements for registration will still have to be followed and the document clearly states that deans will 'continue' to assess young doctors at the end of their F1 year in the same way that they currently do at the end of the PRHO year.

Foundation Year 2 is intended to give a broad base of training, with common learning goals which include those outlined in the GMC document, Good medical practice ${ }^{3}$ (see Box 1). Linked to these will be the acquisition of the core skills and knowledge which will enable trainees to assess and initiate management of patients who present as emergencies, no matter what the clinical scenario.

There are a variety of ways in which these requirements could be met. For example, it could entail three four-month modules in any specialty, so a trainee with a surgical bias could take surgery, $A \& E$ and histopathology; someone with a medical bias could take medicine, general practice and psychiatry, or any other combination. It is hoped, however, to avoid the current preconception that junior doctors must show commitment to their specialty at this

\begin{tabular}{l} 
Box 1. Training given in Foundation Year 2, \\
including learning goals outlined in Good \\
medical practice. ${ }^{3}$ \\
\hline Good clinical care \\
- History taking, examination and note keeping \\
- Time management, risk management and \\
decision making \\
Communication skills \\
- Within a consultation \\
- Wreaking bad news \\
- Complaints \\
Maintaining good medical practice \\
- Learning and teaching \\
- Evidence, audit and guidelines \\
Maintaining trust \\
- Professional behaviour \\
- Patient partnership and health promotion \\
Working with colleagues \\
Teaching and training
\end{tabular}

Ed Neville MD FRCP, Director of Training, General Professional Training Department, Royal College of Physicians

Clin Med 2003;3:529-31 
early stage. It should be seen as advantageous not to do so, in that the broader the base the future consultant physician has, the better physician he or she is likely to become.

This is not the only model and the London Deanery is piloting a model based around A\&E which will facilitate training in the acutely unwell. ${ }^{4}$ There are likely to be other possible scenarios, all of which should allow the trainees to achieve the same educational goals. Learning programmes to achieve these goals include Laying the foundations of good medical practice 5 and the London Deanery Managing life programme. ${ }^{6}$

At some stage in F2 there will be competitive entry to the various programmes of Basic Specialist Training, in our case a medical programme. The others are surgery, psychiatry, general practice, obstetrics and gynaecology, paediatrics and child health, anaesthetics and possibly ophthalmology.

\section{Basic Medical Training}

It seems likely that the first two years of Basic Medical Training (BMT1 and 2) will be very similar to what we currently recognise as an SHO rotation in medical specialties. The College has for a number years been recommending that rotations are changed to four-month modules, and that there should be a three-year training programme, with MRCP to be passed during this period of time. We would hope to encourage most trainees to pass the exam during BMT2, but failure to do so should not prevent them progressing to BMT3 (Table 1).

BMT3 could consist of similar four-month modules in other specialties or could include such posts as are currently standalone posts, known as SHO3 in some areas, which could supply specialist training in disciplines such as neurology or dermatology, or in some areas may operate as old-fashioned medical registrars in smaller district general hospitals.

\section{BMT4 (Higher Specialist Training 1)}

This will be the final year of Basic Medical Training and could also double as the first year of Higher Specialist Training. It is entirely possible that at the end of BMT4 trainees who have satisfactorily completed their training and demonstrated appro-

Table 1. Schematic representation of Basic Medical Training.

\begin{tabular}{|c|c|c|c|}
\hline $\mathrm{F} 1$ & 1 & PRHO & Foundation \\
\hline $\mathrm{F} 2$ & 2 & $\mathrm{SHO}$ & years \\
\hline $\begin{array}{l}\text { BMT1 } \\
\text { BMT2 } \\
\text { BMT3 }\end{array}$ & $\begin{array}{l}3 \\
4 \\
5\end{array}$ & $\begin{array}{l}\text { Medical } \\
\text { programme }\end{array}$ & $\begin{array}{l}\text { Basic } \\
\text { Medical } \\
\text { Training }\end{array}$ \\
\hline $\begin{array}{l}\text { BMT4 } \\
\text { Double } \\
\text { counts as } \\
\text { HST1 }\end{array}$ & 6 & & $\begin{array}{l}\text { GIM - ?MAU } \\
1^{\text {st }} \text { year specialty }\end{array}$ \\
\hline
\end{tabular}

BMT = Basic Medical Training; F1 = Foundation Year $1 ;$ HST = Higher Specialist Training. priate competencies should be awarded a Certificate of Completion of Specialist Training (or Certificate of Completion of Training (CCT) as it will be in the future) in general internal medicine (GIM).

At present the penultimate year assessment that might be performed at the end of BMT3 to allow progression into BMT4 is probably not sufficiently robust to withstand legal challenge. It is therefore currently the College's recommendation that if this programme does come into being there should again be a competitive interview for entry into the final year. It is envisaged, however, that this will only be a temporary arrangement until proper assessments have been piloted and are deemed to be robust.

This final year could be organised in several different ways. There may be six- or 12-month appointments, which could be to a medical assessment unit (MAU); or it could remain as now, with attachment to general internal medicine and a specialty; or there may be the opportunity to meet individual needs.

In order to obtain a CCT in GIM it is a European law requirement that there should be five years training after registration. Thus F2 could count as the first year, and the subsequent four years would make up the five that are legally required. However, for these programmes to produce doctors who are competent to practise general medicine, there will have to be very careful examination of the curricula and the delivery of the training therein, allied to robust assessment. There is no reason why in five or six years time such satisfactory training programmes should not be in place. However, huge anxieties over the transition period are likely, so these new training programmes will probably be introduced progressively, rather than in the 'big bang' style associated with Calman. There will therefore have to be special arrangements for all doctors who are currently in the system, allowing them to progress through training much as we currently recognise it. The current GIM Specialist Advisory Committee (SAC) of the Joint Committee of Higher Medical Training will continue to supervise this.

\section{Future of GIM training}

The difficulties of the transition period should not be underestimated, but it is hoped that the function of the General Professional Training Department, which has joined with the Scottish IMSPEC (Intercollegiate Medical SHO Inspection Committee) to form the Joint Committee on Basic Medical Training (JCBMT) should fuse with the function of the GIM Specialist Advisory Committee over time. It is likely, therefore, that the JCBMT will, in the distant future, also supervise the Higher Specialist Training function of awarding a GIM CCT. The precise mechanisms for this will evolve in the coming years.

The College is encouraging the emergence of the acute physician, who can be specially trained to lead a medical admission (or assessment) unit. At the moment there is a proposal that such individuals may require an extra year of top-up training after their CCT in GIM. In some large units the MAU of the future may be entirely staffed by such acute physicians, rather than by other specialists visiting to do a post-take ward round. 


\section{Specialty training}

Whether or not individuals will have to be interviewed for year 4 of their BMT, they will certainly have to be interviewed for entry into Higher Specialist Training during BMT3. They will then progress to the other two to four years that are prescribed by the individual SACs and achieve a CCT in the specialty at the end of that period of time, much as now.

It is difficult to forecast what the precise relationship will be between general medicine and specialty care for individuals at this stage of their training. If a doctor has a CCT in GIM while being a trainee in a medical specialty, he or she will need to be revalidated in GIM and there are clearly several ways in which this could be achieved. One possible scenario is that these individuals will be regarded as consultants in GIM while they are trainee Fellows in the specialty. There are contractual issues that would have to be worked out and it may be that the profession would need a new title for these individuals.

There are potential advantages to this new system in that there should be more physicians trained to manage acute take and MAU training can easily be added. There are, however, uncertainties, such as where the specialty training will take place. This may have to be worked out on an individual specialty basis and it is not the intention that middle grades should be removed from smaller hospitals. However, as we move from time in training to competency assessment this should be easier to manage, as many competencies for specialties can be acquired just as well in smaller hospitals as in larger ones.

\section{Areas of potential concern}

1 Loss of service If new money is not available for the F2 year then it is likely that either current SHOs or trust doctors at SHO grade will be moved into these slots, with consequent loss of service provision. This is a problem that should be brought to the attention of all trust chief executives.

2 Overseas doctors The NHS has for many years been supported by large numbers of overseas doctors in the training grades. Many of them have subsequently stayed in the UK to provide service as trained doctors and some have gone home. Modernising medical careers provides a wonderful opportunity to arrange appropriate training for our overseas colleagues to allow them to enter medical programmes, pass the MRCP, perhaps obtain a GIM CCT and some training appropriate to them to take back to their country of origin, if that is what they wish to do. The document is disappointingly light in this area.

3 Academic training There is again very little mention of academic training in the document and although this may be relevant to only a small number of doctors these are the crucially important individuals who will take the profession forward into the next generation.

4 The document states that non-consultant career grades (NCCGs) should be aided and facilitated to acquire a CCT. It is disappointing that there are no details as to how this might be achieved.

\section{Conclusion}

Senior house officers have been regarded as the workhorses of the NHS for too long. Improvements in their training and career opportunities are long overdue. The College broadly welcomes the principles underlying these reforms, though there are several issues that are still unclear and need to be worked through. It is important that at the Department of Health launch it was agreed that several aspects would be piloted, in particular Foundation Year 2 which commenced in August 2003.

At the launch it was also stated that there would be a major implementation of Foundation Year 2 in August 2004. This is an ambitious timetable but with hard work can be achieved.

To end on a philosophical note, the word 'modernise' can mean renovate, streamline, redo, redecorate, refurbish, refurnish, update, do-over, rejuvenate, refresh, revamp, redesign, remodel, refashion or remake. This modernisation will hopefully mean rejuvenation rather than merely redecoration.

\section{References}

1 Department of Health. Unfinished business: proposals for reform of the senior house officer grade - a paper for consultation. London: DH, 2002.

2 Department of Health. Modernising medical careers: the response of the four UK Health Ministers to the consultation on unfinished business: proposals for reform of the senior house officer grade. London: DH, 2003.

3 General Medical Council. Good medical practice. London: GMC, 2001. www.gmc-uk.org

4 Paice E, Heard S. Modernising medical careers: a proposal for London. London Deanery, March 2003.

5 Royal College of Physicians. Laying the foundations for good medical practice: a generic training programme for senior house officers. Report of a working party. London: RCP, 2003.

6 London Deanery. Managing Life in the NHS programme. London Deanery. www.londondeanery.ac.uk 